DOI - 10.21707/gs.v10.n02a08

\title{
Cancro do Castanheiro em Trás-os-Montes (Portugal): Incidência atual e estudo da estrutura populacional de Cryphonectria parasitica para a introdução da luta Biológica por HipovirulênCia
}

\author{
Eugénia Gouveia ${ }^{1}$; Eric Pereira ${ }^{1}$; Arsénio Araújo ${ }^{1}$ V Valentim Coelho $^{1}$; João Castro ${ }^{1}$, Helena Bragança $^{2}$ \& Luís Martins ${ }^{3}$
}

\author{
1 Instituto Politécnico de Bragança, Campus de Santa Apolónia 5300-25, Bragança, Portugal, egouveia@ipb.pt \\ 2 INIAV.Av. da República, Quinta do Marquês, 2780-157 Oeiras, Portugal \\ 3 Universidade Trás-os-Montes e Alto Douro, Quinta dos Prados, 5001-801 Vila Real, Portugal
}

Recebido em 02 de novembro de 2015. Aceito em 24 de setembro de 2016. Publicado em 09 de dezembro de 2016.

\begin{abstract}
Resuмo - O castanheiro europeu (Castanea sativa Mill.) é a árvore central de um sistema agroflorestal extensivo e multifuncional muito característico das montanhas do nordeste de Portugal. A introdução do fungo Cryphonectria parasitica (Murrill) Barr que provoca no castanheiro cancros nos tecidos corticais é desde a sua introdução, em 1989, a principal causa de morte do castanheiro. Não existindo meios de luta eficazes a remoção dos cancros é utilizada para reduzir o inóculo do parasita. O método evidenciou pouca eficácia e a doença está presente em todas as regiões de castanheiro. A Hipovirulência, mediada pela presença do hipovírus CHV1, é um método muito eficaz para o tratamento dos cancros e recuperação dos castanheiros. Foi objetivo deste trabalho avaliar a estrutura da população de C. parasitica para introduzir a Hipovirulência. Em 3 freguesias, onde a doença está presente desde a sua introdução, foi estudada a estrutura populacional do fungo parasita. Numa malha geográfica de 500x500m, 70 pontos de amostragem e 1331 castanheiros foram estudados. A análise geoestatística revelou focos de grande intensidade da doença que variaram de 54,75 a 73,33\%. Foram identificados 5 vc types. EU-11 é o grupo dominante com 85,55\%, seguido do EU01 (5,34\%), EU66 (4,58\%) e EU12 (2,90\%), considerados novas introduções do parasita. O idiomorfo MAT-1 e MAT-2 estão presentes nas populações estudadas, sendo o MAT-2 dominante. A proporção 1:1 identificada, num dos locais, sugere multiplicação sexuada do fungo. A ainda baixa diversidade vc type na população de C. parasitica aconselha a introdução da Hipovirulência como meio de luta preferencial contra o Cancro do Castanheiro em Portugal.
\end{abstract}

Palavras-chave: Cryphonectria parasitica (Murrill) BarR., Georeferencia, Geoestatística, Incompatibilidade Vegetativa, Mating type

\section{Chestnut Blight in Trás-os-Montes region (Portugal): Current incidence and Cryphonectria parasitica population study for} INTRODUCTION OF BIOLOGICAL CONTROL BY HYPOVIRULENCE

Aвstract - Chestnut (Castanea sativa Mill) is an ancient and low input agroforestry system of the Portuguese Northeast Mountains. Chestnut Blight that triggered a disturbing epidemics, which became a major cause of chestnut tree mortality after its establishment in 1989, is associated with Cryphonectria parasitica (Murrill) Barr, an invasive alien aggressive plant pathogens. Disease control is attempted by canker removal which was not efficient and disease has continuously increase and spread. Biological control by hypovirulence, a hypovirus CHV1 mediated system, is an efficient method to control the disease and improve the host plant recovery. The main goal of this work was obtaining, the rational for applying hypovirulence to control Chestnut Blight in Portugal. In three parishes, where the chestnut blight is present since its introduction, and applying the georeferencing methods the spread and the genetic population structure of C. parasitica was evaluated. In a 500x500m geographic grid, 70 sampled points and 1331 trees were evaluated. The geostatistical analysis showed widespread distribution of the disease with outbreaks with high incidence of the disease varying from $54.55 \%$ to $7333 \%$. Overall, five vc types were found. EU-11 is the dominant vc type comprising $85.50 \%$ of the isolates, followed by EU01 (5.34\%), EU66 (4.58\%) and EU12 (2.90\%), that were considered new introductions of the parasite. MAT-1 and MAT-2 were identified in all study sites. MAT-2 is dominant but in one location near 1:1 that configure sexual reproduction. The still low diversity of vc type in the C. parasitica population recommend hypovirulence introduction as a preferential mean to control Chestnut Blight in Portugal.

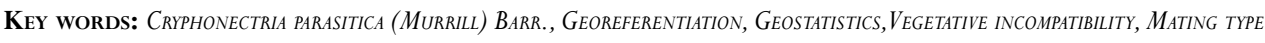

\section{TíTULO EM ESPANHOL}

Resumen - El castaño (Castanea sativa Mill.) es el árbol central de un sistema agroforestal multifuncional muy característico de las montañas del nordeste de Portugal. La introducción del hongo Cryphonectria parasitica (Murrill) Barr, que causa los chancros en el tejido cortical, es desde su introducción en 1989, la principal causa de muerte de los castaños. En ausencia de medios de control eficazes la eliminación de los chancros se utiliza para reducir el inóculo del parásito El método demostró poca efectividad y la enfermedad está presente en todas las regiones de la castaña de Portugal. El hipovirulencia, mediada por la presencia de virus CHV1 (dsRNA) es un método muy eficaz para el tratamiento de los chancros y la recuperación de los castaños. Este estudio tuvo como objetivo evaluar la estructura de la población C. parasitica para aplicar la hipovirulencia. En tres lugares, donde la enfermedad está presente desde su introducción, se estudió la estructura poblacional del hongo parásito. Usando una malla geográfica de 500x500m, se estudiaron 70 puntos de muestreo y 1331 castaños. El análisis geoestadística reveló focos de alta intensidad de la enfermedad que van desde 54,75 a 73,33\%. Se identificaron 5 vc. types. EU-11 és el grupo dominante con 85,55\%, seguido por el EU01(5,34\%), EU66(4,58\%) y EU12(2,90\%). Los idiomorfos MAT-1 y MAT-2 están presentes en las poblaciones estudiadas y la MAT-2 és dominante. La proporción 1:1 se identificó lo que indica la multiplicación sexual del hongo. La baja diversidad vc type en la población de C. parasitica recomienda la introducción de hipovirulencia para controlar el chancro del castaño en Portugal.

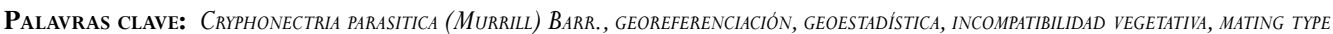

\section{INTRODUÇÃO}

O Cancro do Castanheiro provoca cancros corticais nos troncos e ramos levando á morte das árvores num período curto de tempo. É uma doença bem conhecida em fitopatologia e um exemplo clássico de catástrofe ecológica associado à introdução, nos EUA, do fungo Cryphonectria parasitica (Murrill) Barr, anteriormente Endothia parasitica (Murrill) P.J.
Anderson \& H.W. Anderson, um fungo da micoflora natural dos castanheiros asiáticos (Castanea crenata Siebold et Zucc. e Castanea mollissima Blume). A infeção foi descrita pela primeira vez em castanheiros americanos em 1904 (Farlow, 1912) e rapidamente se instalou em toda a área de dispersão natural do Castanea dentata (Marsh.) Borkh, tendo destruído, em 50 anos, mais de 3,5 mil milhões de castanheiros americanos (Anagnostakis et al. 1988). Na Europa, a doença foi referenciada 
pela primeira vez no Norte da Itália, em 1938, e causou grande preocupação uma vez que o parasita evidenciou, de igual forma, elevada agressividade no castanheiro europeu (Castanea sativa Mill). O parasita progressivamente invadiu os países vizinhos onde se desenvolveu de forma epidémica, estando presente, nos finais da década de 90, em toda a área de distribuição do castanheiro europeu (base de dados PQR-OEPP versão 5.3, 2014). Apesar dos elevados prejuízos e grande número de castanheiros entretanto mortos pela doença, o aparecimento natural da Hipovirulência, a maior tolerância do castanheiro europeu ao fungo parasita e a distribuição não contínua das áreas de castanheiro, permitiu que não se atingissem os níveis de mortalidade observados nos EUA (Heiniger e Rigling 1994, Milgroom e Cortesi 2004).

Em Portugal, o Cancro do Castanheiro teve desenvolvimento epidémico a partir de 1989 quando foi detetado em Carrazedo de Montenegro e quase em simultâneo em Vinhais e Bragança. Atualmente está presente em todas as regiões de castanheiro do país caracterizando-se em termos de distribuição espacial pela existência de focos de forte incidência da doença, com elevado número de árvores doentes, e outros locais com menor extensão e severidade (Gouveia et al. 2001, Bragança et al. 2005). Não existindo substâncias químicas capazes de travar o desenvolvimento dos cancros, os meios de luta utilizados em Portugal baseiam-se na eliminação dos tecidos doentes com o objetivo de reduzir o inóculo do parasita. O método é muito laborioso e pouco eficaz (Gouveia et al. 2003) colocando o ecossistema castanheiro numa situação de grande fragilidade. A Hipovirulência é um método de luta biológico de grande eficácia quando se conhece a estrutura da população do fungo parasita e se aplicam as estirpes hipovirulentas compatíveis (Anagnostakis et al. 1986, Heiniger e Rigling 1994).

A Hipovirulência, mecanismo biológico associado à redução da agressividade em $C$. parasitica, está associada à presença no citoplasma do fungo parasita de partículas dsRNA, atualmente classificadas como vírus da família Hypoviridae e género Hypovirus designado CHV (Cryphonectria parastica Hypovirus). Os vírus dsRNA associados à Hipovirulência não possuem uma fase exterior ao fungo ocorrendo a transmissão entre isolados por anastomose das hifas (Gobbin et al. 2003). A anastomose é viável quando os indivíduos possuem os mesmos alelos em todos os vic loci e incompatíveis quando os alelos são diferentes num ou mais vic loci (Milgroom e Cortesi 1999). Em C. parasitica estão caraterizados seis loci o que determina um total de 64 grupos de incompatibilidade vegetativa (vc type) (Cortesi Milgroom 1998). A eficácia da Hipovirulência como meio de luta biológica depende da estrutura da população do fungo parasita presente em cada local e da capacidade de conversão das estirpe hipovirulentas a introduzir como agentes de controlo biológico. A aplicação da Hipovirulência como meio de luta do Cancro do Castanheiro não foi ainda possível em Portugal uma vez que a estrutura da população relacionada com os vic genes é dominada pelo vc type EU11 um grupo relativamente raro na população europeia e para o qual não se conheciam ou não estavam disponíveis estirpes hipovirulentas.
É objetivo deste trabalho avaliar a incidência e severidade do Cancro do Castanheiro nos locais iniciais de introdução da doença aplicando os métodos de georreferenciação e geoestatística e avaliar a atual estrutura genética da população de C. parasitica quanto ao sistema de incompatibilidade vegetativa (vc type) e de mating type para possibilitar a introdução da Hipovirulência como meio de luta preferencial contra o Cancro do Castanheiro em Portugal uma vez que foram entretanto identificadas estirpes hipovirulentas compatíveis com o grupo vc type dominante em Portugal.

\section{Material e Métodos}

Dispersão e Incidência atual do Cancro do Castanheiro em Portugal

Local de estudo e amostragem das parcelas

Depois de analisados os diversos locais onde a presença do Cancro do Castanheiro é conhecido desde a introdução de C. parasitica em Portugal foram selecionadas as freguesias de Parada (concelho de Bragança), Vilar de Peregrinos (concelho de Vinhais) e São João da Corveira (concelho de Valpaços) (Figura 1). A recolha de dados de campo ocorreu entre maio e agosto de 2013. Na área de cada freguesia foi criada uma rede sistemática de pontos com distância de $500 \mathrm{~m}$ entre parcelas. Na sistematização, usou-se como referência a malha quadrada do Inventário Florestal Nacional, com distância de $2 \mathrm{~km}$ entre pontos. Para a recolha de informação no campo foram previamente desenvolvidos procedimentos idênticos de modo a que a recolha da informação no terreno fosse o mais uniforme possível. A área de amostragem foi também ajustada, de acordo com a situação concreta, para 1000, 1500, ou 2500 $\mathrm{m}^{2}$, de modo a que pudessem incluir pelo menos 15 árvores por parcela. Nos castanheiros foram considerados os parâmetros dendrométricos (idade, diâmetro, altura, diâmetro de copa, variedade), de vigor e de sanidade. A condição fitossanitária (severidade) relacionada com o Cancro do Castanheiro foi avaliada por aplicação de uma escala de 1 a 5 , sendo 1 uma árvore morta e 5 a melhor condição. A presença de cancros foi igualmente registada, sendo recolhido material para isolamento em laboratório.

As árvores foram georreferenciadas, havendo também a georreferenciação do centro da parcela onde ficam incluídos os diversos parâmetros relativos à parcela: i) qualidade do local (litologia, profundidade do solo, exposição, topografia, altitude, declive, pedregosidade); ii) povoamento (idade, copado, área basal, variedade, densidade, estrutura, composição); iii) práticas culturais (lavouras, sobcoberto, fertilizações, corretivos orgânicos, podas, tratamentos fitossanitários); iv) outros parâmetros (valorização ou desvalorização do local).

A aproximação às parcelas foi realizada no terreno com a ajuda de um recetor de sinal GPS e a identificação do centro da parcela com a ajuda fotografia aérea, após a devida marcação num Sistema de informação Geográfica (SIG). Na Figura 1 está representada a localização das freguesias, sendo a distribuição das parcelas proporcional à dimensão de cada uma das 
freguesias e respetiva área de souto em Parada (Bragança), Vilar de Peregrinos (Vinhais) e São João da Corveira (Valpaços).

A análise de dispersão do cancro realizou-se por métodos geoestatísticos, onde é feito o estudo de um semivariograma empírico. O semivariograma faz a representação gráfica da semivariância de pares de amostras similares. Neste caso, considera-se a posição geográfica das árvores e a condição fitossanitária. A correlação espacial é definida considerando uma dada distância (h) entre árvores, i.e., a distância entre cada par de amostras. Quando a semelhança entre pares de valores aumenta, cresce o valor do semivariograma (Isaaks e Srivastava
1989, Pannatier 1996). É possível observar os seguintes valores no semivariograma: patamar, valor da semivariância no modelo platô, igual à variância da amostra, b) efeito de pepita, valor da semivariância na origem; c) a distância entre pares, na qual ainda há boa correlação espacial, que ocorre até ser atingido o patamar do modelo. A partir dessa distância limite os pares deixam de estar correlacionados (Matheron 1962, Shukla et al. 2004, Mulla 2008). A dependência espacial pode ser classificada assumindo o efeito de pepita como uma percentagem relativa ao patamar: $<25 \%$ - forte; $25-75 \%$ - moderada; $>75 \%$ - fraca dependência espacial (Cambardella et al. 1994).

Figura 1 - Localização das áreas de estudo: Parada, São João da Corveira e Vilar de Peregrinos

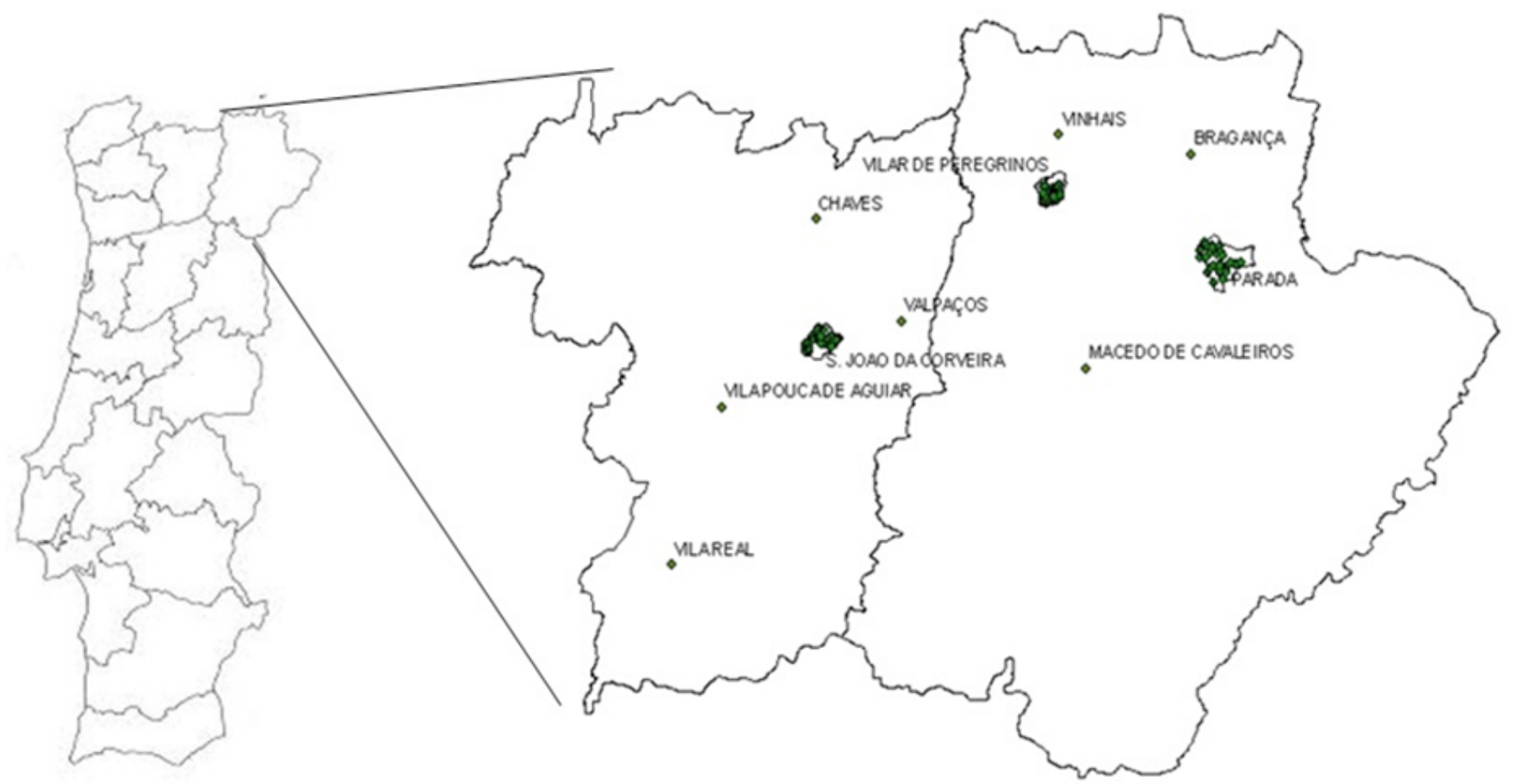

Estrutura genética da População de Cryphonectria parasitica

Recolha das amostras de Cryphonectria parasitica

Todas as árvores dos locais amostrados foram avaliadas, por observação visual, para detetar sintomas da doença nos castanheiros: árvore sã, ramo/árvore morta, casca com necroses e fissuras longitudinais, presença de micélio sob os tecidos do ritidoma do castanheiro. Nas árvores com sintomas visíveis de Cancro do Castanheiro foi retirado material vegetal da zona central e da extremidade do cancro, usando um utensílio de corte. Foram recolhidas amostras de cada um dos cancros presentes por árvore (caso exista) ou de diferentes zonas do cancro devido à extensão do cancro (cancros demasiado extensos). Devido à localização de alguns cancros em locais de difícil acesso tornou-se impossível a recolha de amostras desses cancros. As amostras recolhidas foram colocadas em sacos plásticos, identificadas e transportadas para o laboratório.
Isolamento e caracterização de Cryphonectria parasitica

No laboratório, pequenos pedaços (aproximadamente $5 \times 5 \mathrm{~mm}$ ) foram cortados a partir das amostras com sintomas da doença e desinfetadas por imersão em álcool a 50\% (v/v) durante 3 minutos. Em seguida as amostras foram colocadas em papel absorvente e foram passadas pela chama para retirar todo o excesso de álcool e colocadas em placas de Petri com meio de cultura PDA (Potato Dextrose Agar - Difco, 39 gr/L). As placas de Petri foram incubadas a $25^{\circ} \mathrm{C}$ no escuro durante cerca de 3 dias até obter crescimento micelial para purificar. Após o crescimento micelial, pedaços de micélio são transferidos para novas placas Petri contendo PDA, obtendo assim culturas purificadas. A identificação é realizada por observação das caraterísticas morfológica das culturas, sendo posteriormente incubadas a $25^{\circ} \mathrm{C}$ durante 14 dias à luz difusa do laboratório com o objetivo de obter esporos. 
Grupos de compatibilidade vegetativa (vc type)

Para determinar os grupos de compatibilidade vegetativa (vc types) efetuaram-se pareamentos de todos os isolados com os EU testers já conhecidos em Portugal, EU-01, EU-02, EU11, EU-12 e EU-66 (Bragança et al. 2007) Os isolados de $C$. parasitica foram pareados aproximadamente a $3 \mathrm{~mm}$ de distância na extremidade de placas de Petri e incubados a $25^{\circ} \mathrm{C}$ no escuro durante 7 dias e seguidos de mais 5 dias com exposição à luz difusa do laboratório. As placas de Petri foram inoculadas segundo a metodologia usada por Cortesi et al. (1998). A compatibilidade vegetativa foi avaliada aos 7 dias de incubação às escuras e depois aos 5 dias de incubação à luz difusa e de acordo com a resposta "barrage"/ fusão (Anagnostakis 1988, Bissegger et al. 1997), em que fusão das duas colónias significa compatibilidade e "barrage" entre duas colónias significa isolados de compatibilidade diferente. A diversidade dos vc types em cada local de estudo foi calculada usando o índice de diversidade de Shannon \& Wiener $\left(H^{\prime}\right)$ seguindo a seguinte expressão:

$$
H^{\prime}=-\sum_{i=1}^{s} p i \ln p i
$$

Onde pi é a frequência de $i$ vc types em cada população e $s$ é o número total de vc types em cada população.

Mating type

Depois de analisada a distribuição espacial de $C$. parasitica selecionaram-se, nas zonas de maior incidência da doença e em cada uma das freguesias, os locais para avaliação da estrutura de mating type em C. parasitica. O mating type foi determinado para todos os isolados C. parasitica, através de identificação por amplificação dos idiomorfos MAT utilizando os primers M1-GS1
(5'-GACATCACAAGTCGGCTCCCACGAACA-3') e M1GS2-rev( $5^{\prime}$-GTGCTTTGTGTCGTGTATTAATCGCCGC-3') $\begin{array}{lllll}\text { para } & \mathrm{o} & \text { MAT-1 } & \mathrm{e} & \mathrm{M} 2-\mathrm{GS} 2\end{array}$ (5'-GGAAGTTGGGTCCAAAATATGGGTACAG-3') e InvA5n (5' ${ }^{\prime}$ TGAAAGCAGCCTTGATGTCGGCAGCCTT-3') para MAT-2 (Marra and Milgroom 1999, McGuire et al. 2001). A amplificação por PCR foi realizada em 50ul de uma mistura de reação contendo uma mostra de DNA (cerca de 4ul), um par de primers (10uM cada), 10uM dNTPs, 25mM $\mathrm{MgCl}_{2}, 10 \mathrm{X}$ tampão de reação, 5U7ul Taq DNA polimerase. As condições dos ciclos térmicos usadas nas reações foram as seguintes: 4 min a $94{ }^{\circ} \mathrm{C}, 34$ ciclos de $0,5 \min$ a $94{ }^{\circ} \mathrm{C}, 1$ min a $66^{\circ} \mathrm{C}$ e 4 min a $72{ }^{\circ} \mathrm{C}$, e 4 min a $72^{\circ} \mathrm{C}$ para a extensão final. Os produtos da PCR foram fracionados por eletroforese em agarose a 1,6\% a $90 \mathrm{~V}$ usando o marcador molecular plus DNA Ladder de $1 \mathrm{~Kb}$, coradas com GelRed e visualizadas em UV.

\section{Resultados E Discussão}

Dispersão e Incidência atual do Cancro do Castanheiro em Portugal

Durante este estudo foram estudadas 70 parcelas, 25 parcelas em Parada (Bragança), 27 parcelas em São João da Corveira (Valpaços) e 18 parcelas em Vilar de Peregrinos (Vinhais) (Tabela 1), tendo sido observadas em todos os locais de estudo 1331 árvores, das quais 171 árvores apresentavam sintomas da doença. Durante este estudo foram observadas 22 parcelas sem árvores doentes, sete em Parada, nove em São João da Corveira e seis em Vilar de Peregrinos.

A percentagem de castanheiros infetados em Parada foi de 18,60\%; 9,59\% em Vilar de Peregrinos e 10,00\% em São João da Corveira. Nas parcelas que apresentavam árvores doentes, a percentagem de árvores doentes variou entre 4,76\% até 54,55\% em Parada, 3,85\% até 52,94\% em São João da Corveira e 4,76\% até 73,33 em Vilar de Peregrinos.

Tabela 1 - Número de parcelas georeferenciadas, número de árvores observadas, número de árvores doentes e isolados com e sem Cryphonectria parasitica em Parada, São João da Corveira e Vilar de Peregrinos (ano de 2013)

\begin{tabular}{lrrrr}
\hline & Parada & São Joao da Corveira & Vilar de Peregrinos & Total \\
\hline Parcelas & 25 & 27 & 18 & 70 \\
Árvores observadas & 457 & 530 & 344 & 1331 \\
Árvores doentes & 85 & 53 & 33 & 171 \\
Isolados com C. parasitica & 101 & 72 & 38 & 211 \\
\hline
\end{tabular}

A análise de dispersão espacial do Cancro do Castanheiro foi realizada por métodos geoestatísticos, pelo estudo do semivariograma empírico que faz a representação gráfica da semivariância de pares de amostras similares. A análise geoestatística evidenciou uma distribuição generalizada da doença nos três locais em estudo com focos de maior ou menor dimensão com elevada incidência da doença atingindo 54,55 \% de árvores doentes em Parada, 52,92 \% em S. João da Corveira e com 73,33 \% de árvores doentes em Vilar de Peregrinos. Os locais que apresentam maior incidência da doença são também os locais com maior severidade da doença (Figura 2, 3 e 4). 
Figura 2 - Distribuição da incidência e da severidade da doença em Parada (Bragança) no ano de 2013.

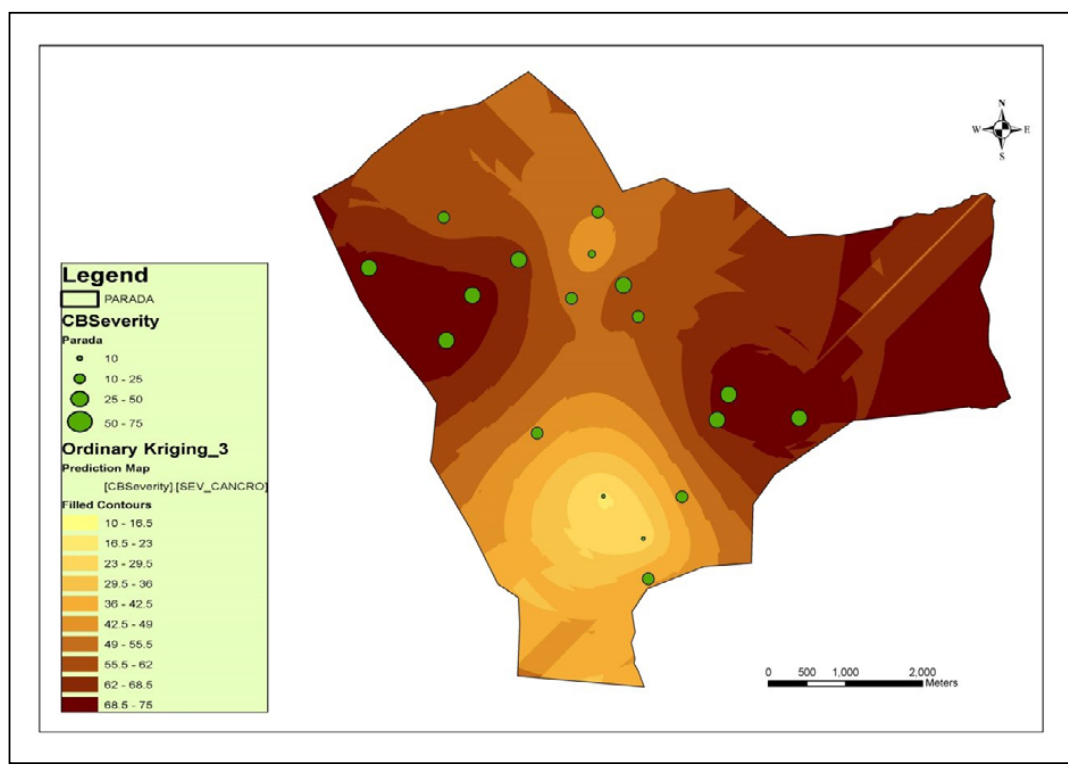

Figura 3 - Distribuição da incidência e da severidade da doença em São João da Corveira (Valpaços) no ano de 2013.

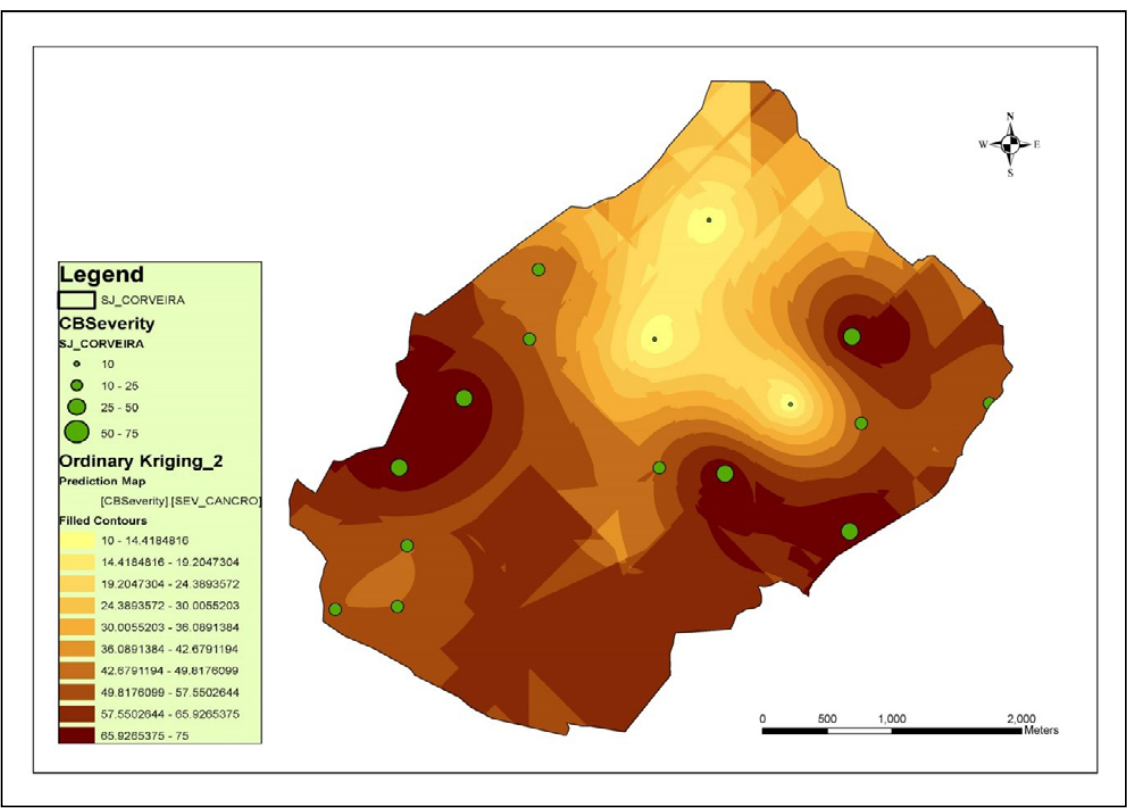

Figura 4 - Distribuição da incidência e da severidade da doença em Vilar de Peregrinos (Vinhais) no ano de 2013.

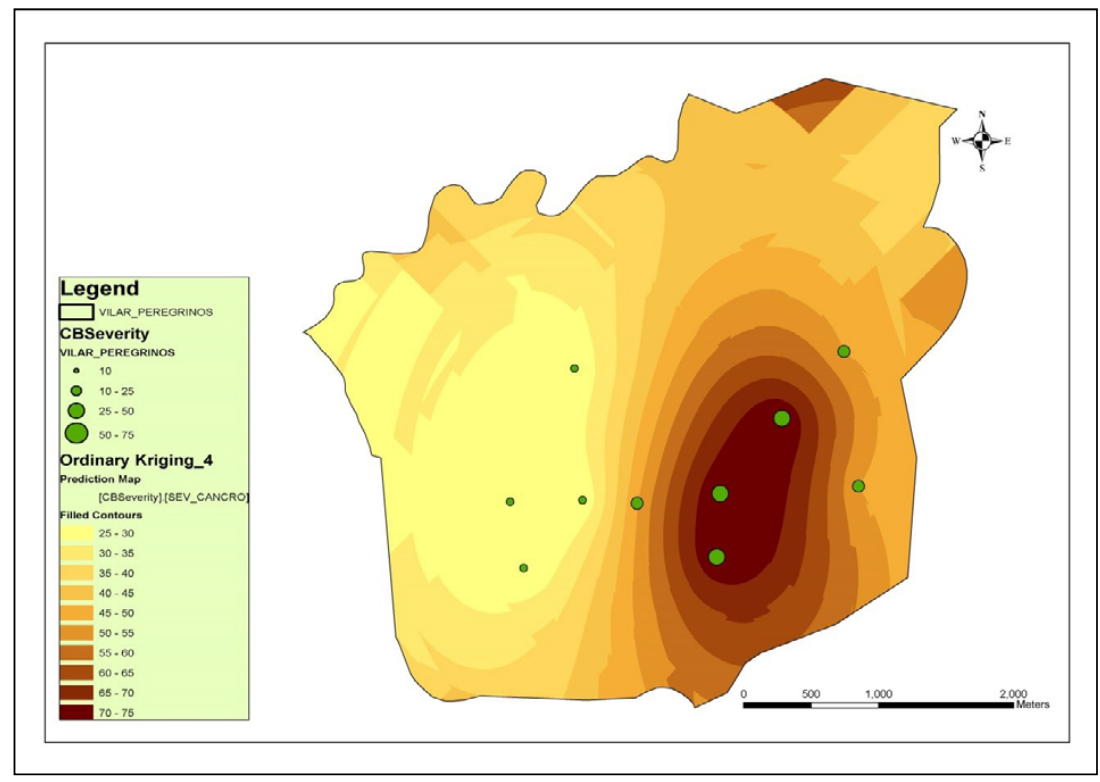


Grupos de compatibilidade vegetativa (vc type)

Das 171 árvores com sintomas de Cancro do Castanheiro das três regiões em estudo analisaram-se 131 isolados de $C$. parasitica. No conjunto dos isolados, foram identificados cinco grupos vc type. O vc type dominante e mais difundido nos três locais de estudo foi o EU11, com 85,50\% e estando presente como grupo dominante em todas as regiões estudadas (Tabela 2). O grupo EU01 foi o segundo vc type mais frequente com $5,34 \%$, seguindo-se o grupo EU66 com $4,58 \%$ e o EU12 com 2,90\% do total dos isolados De referir que em 3 isolados, 1 de Parada (Bragança) e 2 de São João da Corveira (Valpaços), não foi possível determinar o vc type usando os EU testers presentes em Portugal. Analisando por área de estudo, em Parada (Bragança) foram encontrados cinco grupos de vc types, sendo o mais frequente o grupo EU11 (88,31\%), seguindo-se o grupo EU01 (6,49\%), EU12 (2,59\%) e o EU66 (1,29\%).

Em São João da Corveira (Valpaços) foram identificados quatro grupos de vc types, sendo o mais frequente o grupo EU11 (79,41\%), seguindo-se o grupo EU66 (11,76\%) e o EU12 (2,94\%). Em Vilar de Peregrinos foram identificados três grupos de compatibilidade vegetativa, sendo o mais frequente o grupo EU11 (85,00\%), seguindo-se o grupo EU01 (10,00\%) e o EU66 (5,00\%). O índice de diversidade de ShannonWiener $\left(H^{\prime}\right)$ variou de 0,495 em Parada a 0,705 em São João da Corveira.

\section{Mating type}

Um total de 91 isolados de C. parasitica foram testados para mating type, $18 \mathrm{em}$ Parada, $32 \mathrm{em} \mathrm{S}$. João da Corveira e 41 em Vilar de Peregrinos. Em 22 isolados, 10 em Parada, 4 em São João da Corveira e 8 em Vilar de Peregrinos não foi possível obter amplificação de qualquer dos idiomorfos MAT com o método utilizado. Em todos os locais em estudo foi identificado MAT-1 e MAT-2 (Tabela 3).

Tabela 2 - Número de isolados de Cryphonectria parasitica (Murrill) Barr., tipos de compatibilidade vegetativa e Índice de Diversidade Shannon \& Wiener (H’) em Parada, São João da Corveira e Vilar de Peregrinos no ano de 2013.

\begin{tabular}{|c|c|c|c|c|c|c|c|}
\hline \multirow[t]{2}{*}{ Freguesia } & \multirow{2}{*}{$\begin{array}{c}\mathrm{N}^{\mathrm{o}} \text { Isolados } \\
\text { pareados }\end{array}$} & \multicolumn{5}{|c|}{ Compatibilidade Negativa } & \multirow[t]{2}{*}{$H^{\prime}$} \\
\hline & & EU01 & EU11 & EU12 & EU66 & $\mathrm{NC}$ & \\
\hline Parada & 77 & 5 & 68 & 2 & 1 & 1 & 0,495 \\
\hline São João da Corveira & 34 & 0 & 27 & 1 & 4 & 2 & 0,705 \\
\hline Vilar de Peregrinos & 20 & 2 & 17 & 0 & 1 & 0 & 0,518 \\
\hline Total & 131 & 7 & 112 & 3 & 6 & 3 & \\
\hline
\end{tabular}

NC - Não conhecido; $H^{\prime}$ - Índice de Diversidade de Shannon \& Wiener

Tabela 3 -Isolados testados, mating type e proporção (MAT-1/MAT-2) dos isolados encontrados nas freguesias de Parada, São João da Corveira e Vilar de Peregrinos no ano de 2013..

\begin{tabular}{lccccc}
\hline & & \multicolumn{3}{c}{ Mating types } & Proporção \\
\cline { 3 - 4 } Freguesia & Isolados & MAT-1 & MAT-2 & MAT-1 e 2 & MAT-1 / MAT-2 \\
\hline Parada & 18 & 5 & 3 & 0 & $5 / 3$ \\
São João da Corveira & 32 & 13 & 15 & 0 & $13 / 15$ \\
Vilar de Peregrinos & 41 & 12 & 19 & 2 & $12 / 19$ \\
Total & $\mathbf{9 1}$ & $\mathbf{3 0}$ & $\mathbf{3 7}$ & $\mathbf{2}$ & \\
\hline
\end{tabular}


Em São João da Corveira e em Vilar de Peregrinos o idiomorfo MAT-2 foi dominante, com uma relação (MAT1:MAT-2) próxima de 1 em São João da Corveira. Em Parada, o idiomorfo MAT-1, foi dominante. De um modo geral, e considerando todos os isolados dos três locais de estudo, o MAT2 foi o mais abundante, aparecendo em 58,50\% dos isolados, contrastando com 37,74\% pertencendo ao MAT-1. Apesar de se ter obtido uma percentagem muito baixa, apenas 3,77\%, é de registar a presença de isolados com ambos os idiomorfos amplificados no mesmo isolado.

\section{Conclusão}

A doença está generalizada por todas as áreas de estudo tendo sido detetada C. parasitica em 48 parcelas. Nas parcelas onde a doença está presente, a percentagem de castanheiros infetados variou entre 4,76\% a 54,55\% em Parada, 3,85\% a $52,94 \%$ em São João da Corveira e 4,76\% a 73,33 em Vilar de Peregrinos o que evidencia a existência de forte incidência da doença em alguns locais e outros onde a doença não está ainda presente como foi identificado em anteriores trabalhos realizados em Portugal (Bragança et al. 2009). A metodologia de amostragem utilizada nos diferentes trabalhos não permite a comparação direta dos resultados mas a dispersão da doença apresenta um padrão de distribuição espacial semelhante ao encontrado nos estudos anteriormente realizados em Portugal.

Neste estudo foram observados cinco vc types diferentes entre os 131 isolados provenientes de castanheiros infetados de três freguesias da região de Trás-os-Montes (Parada, São João da Corveira e Vilar de Peregrinos). Em Parada, um dos locais inicialmente estudados (Gouveia et al. 2001) e onde foi identificado apenas um grupo vc type, mais tarde identificado como EU-11, apresenta agora mais 4 grupos vc type. De referir que os novos grupos vc type aparecem numa área muito localizada e que a história do local revela novas introduções do parasita. Na grande maioria das parcelas amostradas em Parada apenas foi detetado o grupo anteriormente identificado. Em São João da Corveira e em Vilar de Peregrinos a diversidade vc type apresenta valores semelhantes aos descritos em Bragança et al. (2007) e Gouveia et al. (2010).

A ainda baixa diversidade de vc types encontrada neste estudo contrasta com o elevado número de vc types encontrados em países como Suíça (Bissegger et al. 1997), Itália (Cortesi et al. 1996) e França (Breuillin et al. 2006). O vc type dominante continua a ser o vc type EU-11 representando 85,50\% dos isolados. A presença de outros vc type (EU-01, EU-66;EU-02, EU-12) ainda que minoritários podem contribuir para o aumento da diversidade vc type em populações onde a reprodução sexuada pode ocorrer. O vc type EU-11 é o grupo dominante em Portugal (Bragança et al. 2007) e também muito frequente na província espanhola de Castilha y León (Zamora et al. 2012) é, no entanto, um grupo minoritário na Europa tendo sido encontrados apenas alguns isolados em Itália, França e Croácia (Cortesi et al. 1996, Robin et al. 2000, Krstin et al. 2008).

O mating type foi estudado em 91 isolados dos quais se obteve amplificação dos idiomorfos MAT em 69 isolados. A amplificação dos idiomorfos não foi obtida em todos os isolados, mesmo depois de algumas repetições e foi particularmente acentuado na população de Parada onde não foi possível obter amplificação em mais de 50\% dos isolados. O idiomorfo MAT2 foi o mais frequente em São João da Corveira e Vilar de Peregrinos e o idiomorfo MAT-1 o mais frequente em Parada. Os dois idiomorfos MAT-1 e MAT-2 foram obtidos em todos os locais estudados. Em 2 isolados de Vilar de Peregrinos foram identificados, no mesmo isolado, os dois idiomorfos. Em estudos realizados por Bragança et al. (2007) na região deTrás-os-Montes, foi verificado também que o MAT-2 foi dominante em todos os locais amostrados na região, tendo a relação dos idiomorfos apresentando valores significativamente diferente da proporção 1:1. No entanto os autores concluem, com base na presença de peritecas nos tecidos doentes, que a multiplicação sexual seria comum em Portugal e que estaria associada à introdução inicial de isolados EU-11 com idiomorfos diferentes ou auto-férteis. Neste trabalho foram identificados isolados EU-11 de idiomorfo MAT-1 e outros MAT-2 e ainda isolados com os dois idiomorfos no mesmo isolado. A rápida dispersão da doença em alguns locais e a presença de peritecas observadas nesses locais (não incluídos neste estudo) é indicador da capacidade de multiplicação sexuada do fungo o que potencialmente pode levar a uma rápida alteração da população parasita. A introdução de estirpes C. parasitica CHV1 como meio de luta biológico que sendo maternalmente estéreis (Anagnostakis 1987) e ao não produzem esporos, que atuam como gâmetas masculinos na fertilização das hifas, diminuirão a capacidade de multiplicação sexuada do fungo contribuindo assim para a redução da diversidade do fungo parasita e para a eficácia da Hipovirulência como meio de luta. A presença da Hipovirulência natural é ainda muito reduzida em Portugal tendo sido isolados apenas 8 isolados com fenótipo branco, todos na região de São João da Corveira, e identificados posteriormente com estirpes CHV1 de C. parasitica. A caraterização molecular dos isolados hipovirulentos obtidos na região de Trás-os-Montes (Pereira et al. 2015) possibilitará, a curto prazo, a introdução da Hipovirulência como meio de luta preferencial contra o cancro do Castanheiro em Portugal. A informação recolhida através do sistema de informação geográfico (SIG) e georreferenciação de todos os indivíduos em estudo constitui uma base de dados de referência para estudos posteriores que poderão elucidar muitos aspetos relacionados com a eficácia do método mas também com as alterações futuras ao nível da estrutura da população do fungo parasita.

\section{Agradecimentos}

Este estudo foi financiado pela FCT e programa COMPETE através do projeto PTDC/AGR-PRO/4606/2012 - "HiCC - Luta Biológica por Hipovirulência contra o Cancro do castanheiro em Portugal".

\section{REFERÊNCIAS}

Anagnostakis SL, Hau B and Kranz J. 1986: Diversity of vegetative compatibility types of Cryphonectria parasitica in 
Connecticut and Europe. Plant Disease, 70: 536-538.

Anagnostakis SL. 1987. Chestnut blight: The classical problem of an introduced pathogen. Mycologia, 79: 23-37.

Anagnostakis SL. 1988. Cryphonectria parasitica, cause of chestnut blight. Advances in Plant Pathology, 6: 123-136.

Biraghi A. 1950. Caratteri di resistenza in Castanea sativa nei confronti di Endothia parasitica. Bollettino Mensile della Stazione di Patologia Vegetale, 8:1-5.

Bissegger M, Rigling D and Heiniger U. 1997. Population structure and disease development of Cryphonectria parasitica in european chestnut forests in the presence of natural hypovirulence. Phytopathology, 87: 50-59.

Bragança H, Simões S, Onofre N and Santos N. 2009. Factors influencing the incidence and spread of chestnut blight in Northeastern Portugal. Journal of Plant Pathology, 91(1): 53-59.

Bragança H, Simões S, Onofre N, Tenreiro R and Rigling D. 2007. Cryphonectria parasitica in Portugal - Diversity of vegetative compatibility types, mating types, and occurrence of hypovirulence. Forest Pathology, 37: 391-402.

Bragança H, Simões S, Santos S, Marcelino J, Tenreiro R and Rigling D. 2005. Chestnut blight in Portugal - Monitoring and vc types of Cryphonectria parasitica. Acta Horticulturae, 693: 627-634.

Breuillin F, Dutech C and Robin C. 2006. Genetic diversity of the chestnut blight fungus Cryphonectria parasitica in four French populations assessed by microsatellite markers. Mycological Research, 110: 288-296.

Cambardella CA, Moorman TB, Novak JM, Parkin TB, Karlen DL, Turco RF and Konopka AE. 1994. Field-scale variability of soil properties in Central Iowa Soil. Soil Science Society of America Journal, 58(5): 1501-1511.

Cortesi P e Milgroom MG. 1998. Genetics of vegetative incompatibility in Cryphonectria parasitica. Applied and Environmental Microbiology, 64: 2988-2994.

Cortesi P, Milgroom MG and Bisiach M. 1996. Distribution and diversity of vegetative compatibility types in subpopulations of Cryphonectria parasitica in Italy. Mycological Research, 100: 1087-1093.

Cortesi P, Rigling D and Heiniger U. 1998. Comparison of vegetative compatibility types in Italian and Swiss subpopulations of Cryphonectria parasitica. European Journal of Forest Patholology, 28: 167-176.

EPPO PQR, 2014. Base de dados PQR-OEPP versão 5.3, 2014.

Farlow WG. 1912. The fungus of the chestnut-tree blight. Science, New Series, 35(906): 717-722.

Gobbin D, Hoegger PJ, Heiniger U and Rigling D. 2003. Sequence variation and evolution of Cryphonectria hypoviruses (CHV-1) in Europe. Virus Research, 97: 39-46.
Gonzalez-Varela G, Gonzalez AJ and Milgroom MJ. 2011. Clonal population structure and introductions of the chestnut blight fungus, Cryphonectria parasitica, in Asturias, northern Spain. European Journal of Plant Pathology, 131: 67-79.

Gouveia ME, Cardoso P and Monteiro ML. 2001. Incidence of chestnut blight and diversity of vegetative compatible types of Cryphonectria parasitica in Trás-os-Montes (Portugal). Forest, Snow and Landscape Research, 76: 387-390.

Gouveia ME, Coelho V and Portela E. 2003. Cancro do castanheiro: A luta cultural na redução do inóculo e manutenção sustentada dos soutos. Actas do VI Encontro Nacional de Protecção Integrada. Castelo Branco, 14-16 de Maio, 230236p.

Heiniger U e Rigling D. 1994. Biological control of chestnut blight in Europe. Annual Review of Phytopathology, 32: 581-599.

Hoegger P, Rigling D, Holdenrieder $\mathrm{O}$ and Heiniger $\mathrm{U}$. 2000. Genetic structure of newly established populations of Cryphonectria parasitica. Mycological Research, 104: 11081116.

Isaaks EH e Srivastava RM. 1989. An Introduction to Applied Geostatistics. Oxford University Press. New York. 572 p.

Krstin L, Novak-Agbaba S, Rigling D, Krajacic M and Curkovic Perica M. 2008. Chestnut blight fungus in Croatia: diversity of vegetative compatibility types, mating types and genetic variability of associated hypovirus CHV-1. Plant Pathology, 57: 1086-1096.

Marra RE e Milgroom MG. 1999. PCR amplification of the matingtype idiomorphs in Cryphonectria parasitica, Molecular Ecology, 8: 1947-1950.

Matheron G. 1962. Traité de géostatistique appliquée. Editions Technip.

McGuire IC, Marra RE, Turgeon BG and Milgroom MG. 2001. Analysis of matingtype genes in the chestnut blight fungus, Cryphonectria parasitica. Fungal Genetics Biology, 34: 131 144.

Milgroom MG e Cortesi P. 1999. Analysis of population structure of the chestnut blight fungus based on vegetative incompatibility genotypes. Proceedings of Natural Academy Sciences. USA, 96: 10518-10523.

Milgroom MG e Cortesi P. 2004. Biological control of chestnut blight with hypovirulence: A critical analysis. Annual Review of Phytopathology, 42: 311-338.

Mulla DJ. 2008. Spatial Variability. Dept. Soil, Water \& Climate. University of Minnesota.

PannatierY. 1996. Variowin: Software for Spatial Data Analysis in 2D. Springer-Verlag, New York.

Pereira E, Rigling D, Prospero S and Gouveia E. 2015. Controlo biológico do cancro do castanheiro. Deteção, identificação e caracterização do Hypovirus - CHV1. Revista de Ciências Agrárias, 38(2): 258-263. 
Robin C e Heiniger U. 2001. Chestnut blight in Europe: Diversity of Cryphonectria parasitica, hypovirulence and biocontrol. Forest Snow and Landscape Research, 76: 361-367.

Robin C, Anziani C and Cortesi P. 2000. Relationship between biological control, incidence of hypovirulence, and diversity of vegetative compatibility types of Cryphonectria parasitica in France. Phytopathology, 90: 730-737.

Shukla MK, Slater BK, Lal R and Cepuder P. 2004. Spatial variability of soil properties and potential management classification of a Chernozemic field in lower Austria. Soil Science, 169(12): 852-860.

Sotirovski K, Papasova-Anakieta I, Grunwald N and Milgroom MG. 2004. Low diversity of vegetative compatibility types and mating type of Cryphonectria parasitica in the southern Balkans. Plant Pathology, 53: 325-333.

Zamora P, Martín AB, Rigling D and Diez JJ. 2012. Diversity of Cryphonectria parasitica in western Spain and identification of hypovirus-infected isolates. Forest Pathology, 42: 412-419. 